\title{
BOND STRENGTH TESTS BETWEEN SILICON WAFERS AND DURAN TUBES (FUSION BONDED FLUIDIC INTERCONNECTS)
}

\author{
Imran Fazal, Erwin Berenschot, Rik deBoer, Henri Jansen and Miko Elwenspoek \\ MESA+ Research Institute, University of Twente, Enschede, The Netherlands
}

\begin{abstract}
The fusion bond strength of glass tubes with standard silicon wafers is presented. Experiments with plain silicon wafers and coated with silicon oxide and silicon nitride are presented. Results obtained, are discussed in terms of homogeneity and strength of fusion bond. High pressure testing shows that the bond strength is large enough for most applications of fluidic interconnects. The bond strength for $525 \mu \mathrm{m}$ thick silicon with glass tubes having outer diameter of $6 \mathrm{~mm}$ and with wall thickness $2 \mathrm{~mm}$, is more than 60 bars after annealing at temperature of $800^{\circ} \mathrm{C}$
\end{abstract}

Keywords: Bond strength, Duran tubes, Fusion bonding, Fluidic interconnects, MEMS

\section{INTRODUCTION}

The connection of micro devices to the outside world plays a significant role in MEMS applications such as micro flow controllers, micro reactors and fluidic devices in general. With the increase in demand and priority in device reliability issues, one cannot afford to allow flaws in the quality or complexity in the fluidic interconnects. Reliable fluidic interconnects are one of the basic building blocks of integrated fluidic systems.

In literature, different schemes have been introduced for a variety of interconnections. Few used gluing [1,2], which poses the different problems such as contamination, low operating temperature and misatignment as well. Even high temperature ceramic epoxies were used and were found to be prone to leakage at high temperatures $[3,4]$. Some introduced soldering (eutectic bonding) on silicon [5], which needs an intermediate layer in between two materials to be bonded and can't withstand the high temperature. A few have discussed about press fittings $[6,7]$. Kovar anodic bonding technique has been used to avoid thermal stresses due to considerably less thermal mismatch with Pyrex at high temperature of $400{ }^{\circ} \mathrm{C}$, however thermal stresses induced during processing led to fracture in the silicon [8]. The previous problem was addressed to solve by bonding of Kovar tube to silicon with Pyrex ring, which helps to raise the operating temperature to $600^{\circ} \mathrm{C}$ at high holding pressure of $5 \mathrm{~atm}$. [9].

The technique presented in this paper establishes a reliable packaging technology for connection of MEMS components; operatable even at more than $600{ }^{\circ} \mathrm{C}$. This approach differs from the previous techniques as the interconnections are realized by the fusion bonding of glass tubes to silicon. This is done by annealing the glass tubes to the silicon at their softening temperature of 800 ${ }^{\circ} \mathrm{C}$. First, fabrication of the devices is discussed and subsequently experiments and results are presented and finally conclusions are drawn.

\section{FABRICATION}

This section discusses the surface preparation and annealing conditions of the device. Fusion bonding proceeds by mating of mirror polished surfaces, which are precleaned. At room temperature wafers and tubes positions are fixed by attractive interactions between the hydrophilic surfaces. The wafer and glass tubes adhere at room temperature via hydrogen bridge bonds of chemisorbed water molecules that react during the annealing to form $\mathrm{Si}-\mathrm{O}-\mathrm{Si}$ bonds. With the increase in temperature $\left(400^{\circ} \mathrm{C}\right.$ to $\left.800^{\circ} \mathrm{C}\right)$, oxidation reactions take place, which increase the bond strength at the interface [10].

Standard silicon wafers with $10 \mathrm{~mm}$ diameter and with a thickness of $525 \mu \mathrm{m}$ and glass tubes with $6 \mathrm{~mm}$ diameter were used for the bonding experiments. Standard Duran glass tubes have been chosen to provide this fluidic interconnection, because they are adapted to standard swagelock connectors. Moreover, the almost identical thermal expansion coefficient of glass tubes and silicon up to $400^{\circ} \mathrm{C}$ prevents failure, which is caused by the thermal mismatch during thermal cycling. To observe the difference in bonding behavior, wafers silicon oxide and silicon nitride were used too.

Following three groups of experiments were performed:

1) Bonding of glass tubes to bare silicon.

2) Bonding glass tubes to oxidized silicon.

3) Bonding glass tubes to silicon to nitride layer.

Silicon wafers were cleaned by following a standard procedure; 10 minutes treatment in $100 \% \mathrm{HNO}_{3}$ and in $69 \% \mathrm{HNO}_{3}\left(95{ }^{\circ} \mathrm{C}\right)$ respectively, rinsed in DI water and dried with $\mathrm{N}_{2}$. Standard glass tubes were diced manually into different lengths, cleaned for 20 minutes with $1 \%$ $\mathrm{HF}$ to avoid contamination due to wax used in dicing. After cleaning, wafers were placed in the oven (at 400 
${ }^{\circ} \mathrm{C}$ and at room temperature) and later on glass tubes were positioned on the silicon wafers in the oven for annealing. Table 1 shows the process steps followed in these experiments.

Table 1: Process steps for fusion bonded fluidic interconnects

\begin{tabular}{|c|c|}
\hline $\begin{array}{c}\text { Selection + } \\
\text { Dicing of Glass + } \\
\text { Tubes + Cleaning }\end{array}$ & \\
\hline $\begin{array}{c}\text { Selection of Si } \\
\text { wafer } \\
\text { + Cleaning }\end{array}$ & \\
\hline $\begin{array}{l}\text { Pre Aligning }+ \\
\text { Fusion Bonding }+ \\
\text { Powder Blasting }\end{array}$ & Cross sectional view \\
\hline
\end{tabular}

In our experiments, the wafers with glass tubes were annealed at $800^{\circ} \mathrm{C}$ for 30 minutes in a controlled way with a temperature ramp of $10^{\circ} \mathrm{C}$ per minute as shown in Figure 1 .
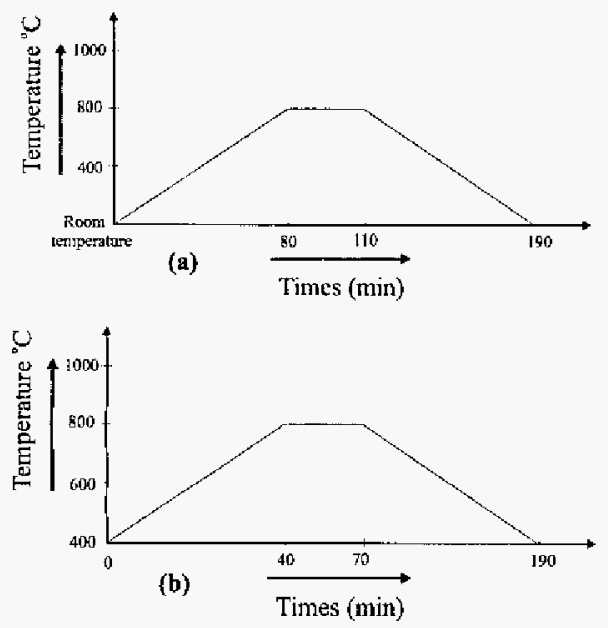

Figure 1: Temperature anneal ramp a) From room temperature up to $800^{\circ} \mathrm{C}$ b) From $400^{\circ} \mathrm{C}$ to $800^{\circ} \mathrm{C}$

Samples were annealed in two different ways as shown in Figure 1, to observe how the quality of the bond is affected by this change. All cleaning steps were performed in clean room but samples were annealed in clean room environment as well as in open lab. The fabricated devices are shown in Figure 2.

The standard Duran glass tubes, diced to the appropriate size of $15-20 \mathrm{~mm}$, have been chosen to provide this fluidic interconnection, because they are adapted to standard swage lock connectors. The glass tubes with outer diameter of $6 \mathrm{~mm}$ and with the wall thickness of 1 and $1.5 \mathrm{~mm}$ were used.

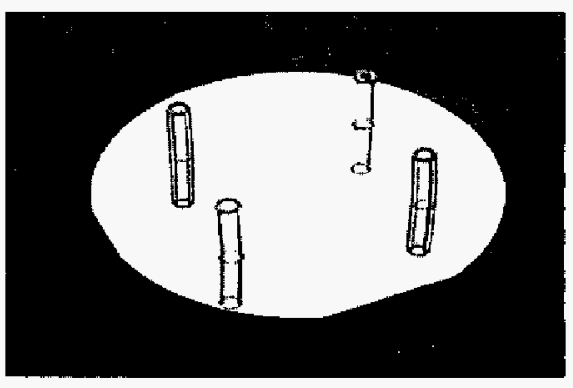

Figure 2: Glass tubes bonded to silicon wafer

In addition, samples with 1 micron of silicon oxide and silicon nitride layers were prepared. The oxide was thermally grown at $1150^{\circ} \mathrm{C}$ to a thickness of 1 micron. Low stress silicon nitride of 1 micron thickness was deposited with LPCVD at $850^{\circ} \mathrm{C}$.

\section{EXPERIMENT}

High-pressure apparatus as shown in Figure 3 was used to test the bond strength of the samples fabricated. The maximum pressure that could be measured by the apparatus was 600 bars. Standard swage locks were used to connect the specimens to the test apparatus through connector and fiber. Water flow rate of $100 \mu \mathrm{l} / \mathrm{s}$ was set to increase the pressure gradually till the sample breaks. The pressure increases at the rate of 15 bars per minute approximately. The maximum pressure at which the sample breaks can be obtained from the data acquisition system.

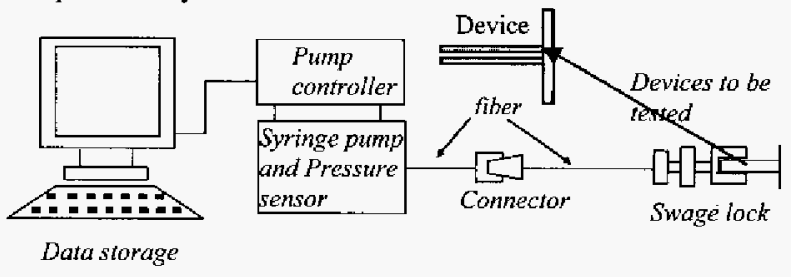

Figure 3: Block diagram of high-pressure experimental apparatus

\section{RESULTS AND DISCUSSIONS}

Prior to experiments, it was observed that, after annealing, the glass tubes with $20 \mathrm{~mm}$ in length were slightly bent as shown Figure 2. It was due to fact that the glass tubes were manually diced, which leaves the tube circumferential surface uneven and caused the glass tubes to bend slightly during annealing at high temperature of $800^{\circ} \mathrm{C}$ (which is close to the softening temperature of Duran glass tubes, $825^{\circ} \mathrm{C}$ ). It was also observed that the glass tubes with $20 \mathrm{~mm}$ length bend more than the tubes with $15 \mathrm{~mm}$ length, which caused problem to connect the specimen with swage lock to perform bond strength test. Moreover, it was observed that there were no non-bonding areas between glass tubes and silicon wafer interface as shown in Fig.4. The 
voids due to particles were expected, as the specimens were prepared in clean room environment as well as in lab. This observation was confirmed after performing bond strength tests.

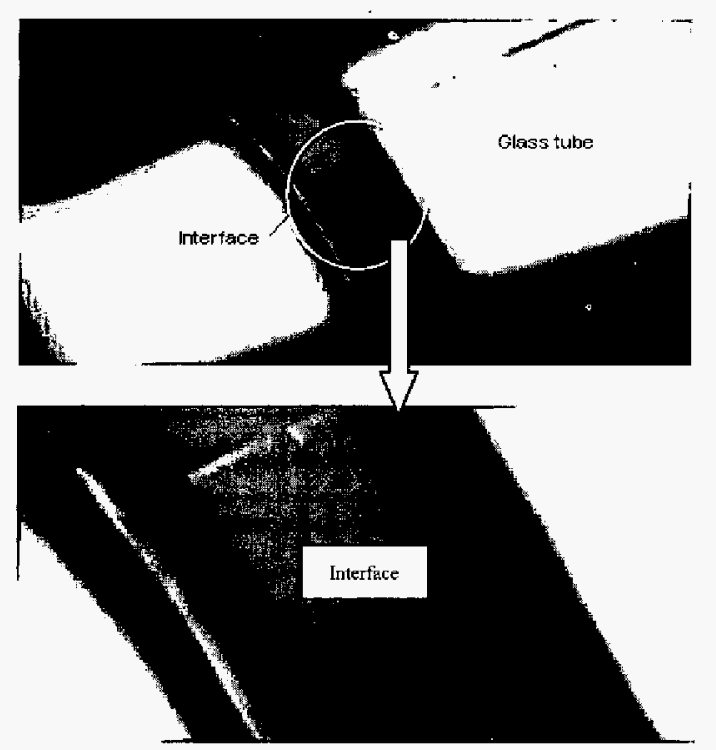

Figure 4: a) Interface view b) Zoom in view of interface

To evaluate the fusion bond strength of an interconnection, statistical tests have been performed using the high pressure set up. Results are presented in Table 2.

Table 2: Burst pressure results for 20 samples each

\begin{tabular}{|c|c|c|c|c|}
\hline Wafer & $\begin{array}{c}\text { Wall } \\
\text { Thickness } \\
\text { (mm) }\end{array}$ & $\begin{array}{c}\text { Tube } \\
\text { Inner } \\
\text { Diameter } \\
\text { (mm) }\end{array}$ & $\begin{array}{l}\text { Average } \\
\text { Burst } \\
\text { Pressure } \\
\text { (bars) }\end{array}$ & $\begin{array}{c}\text { Standard } \\
\text { Deviation } \\
\sigma \\
\text { (bars) }\end{array}$ \\
\hline Silicon & $\begin{array}{l}1.0 \\
1.5 \\
\end{array}$ & $\begin{array}{l}4 \\
3 \\
\end{array}$ & $\begin{array}{l}43 \\
65 \\
\end{array}$ & $\begin{array}{l} \pm 2.7 \\
\pm 4.0 \\
\end{array}$ \\
\hline $\begin{array}{c}\text { Silicon } \\
\mathrm{SiO}_{2}\end{array}$ & $\begin{array}{l}1.0 \\
1.5\end{array}$ & $\begin{array}{l}4 \\
3\end{array}$ & $\begin{array}{l}43 \\
65\end{array}$ & $\begin{array}{l} \pm 0.8 \\
\pm 1.7\end{array}$ \\
\hline$\underset{\mathrm{Si}_{3} \mathbf{N}_{+}}{\text {Silicon }}$ & $\begin{array}{l}1.0 \\
1.5\end{array}$ & $\begin{array}{l}4 \\
3\end{array}$ & $\begin{array}{l}20 \\
31\end{array}$ & $\begin{array}{l} \pm 1.0 \\
\pm 1.7\end{array}$ \\
\hline
\end{tabular}

It is found from this table that in case of plain silicon, the average burst pressure was 43 bars and 65 bars for the glass tubes with the wall thickness of $1 \mathrm{~mm}$ and $1.5 \mathrm{~mm}$ respectively. There was $50 \%$ increase in the burst pressure with $50 \%$ increase in wall thickness. It was also observed that in case of large thickness of the tube, breakage was observed in silicon while in case of smailer wall thickness, the glass tubes split from the silicon by leaving some traces of glass on it as shown in Fig 5 a, b.

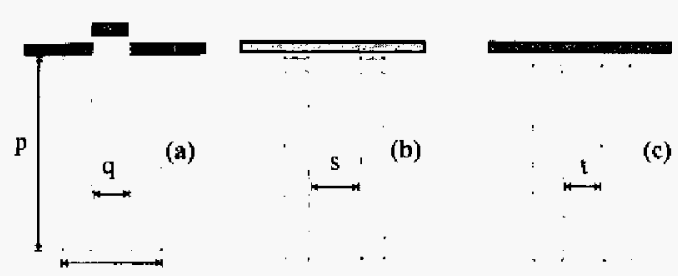

Figure 5: a) Breakage in silicon b) Traces of glass on silicon wafer c) No breakage in glass and in silicon

Parameters shown in Figure 3 are given in Table 3 .

Table 3: Geometrical parameters

\begin{tabular}{|c|c|c|c|c|c|}
\hline Parameters & $\mathrm{p}$ & $\mathrm{q}$ & $\mathrm{r}$ & $\mathrm{s}$ & $\mathrm{t}$ \\
\hline mm & 15 & 3 & 6 & 4 & $3-4$ \\
\hline
\end{tabular}

The burst pressures in case of the oxide layer is identical with bare silicon. However, the burst pressure differs significantly in case of a silicon nitride layer. The minimum and the maximum burst pressures found were 20 and 30 bars respectively. No breakage in silicon and no traces of glass were found on the silicon nitride as shown in Figure $5 \mathrm{c}$.

This low burst pressure results in case of silicon nitride layer, as silicon nitride is dense and hard material. The dense structure of silicon nitride does not provide the open channels found in the oxide structures, so oxygen diffuses very slowly through the nitride and prevents oxidation of underlying layer. So in case of native oxide layer bond strength quality is good as interfacial oxide grows almost completely at high annealing temperature of $800{ }^{\circ} \mathrm{C}$. It was also observed that there was no considerable difference in bond strength for the specimens, prepared in clean room and in the normal lab ( $65 \pm 3$ bars).

The burst pressure obtained during experiments is high enough for the applications in Microsystems such as for micro flow controllers, micro reactors and fluidic devices in general. But theoretically the real values are far above the burst pressure values. And it is assumed that this difference is due to the thermal stresses produced due to thermal mismatch of glass tubes and silicon at high temperatures. It can be seen from Figure 6 , the thermal expansion coefficient for Pyrex increases rapidly above $450{ }^{\circ} \mathrm{C}$. (Pyrex and Duran, both are borosilicate glass, thus having almost same properties) 


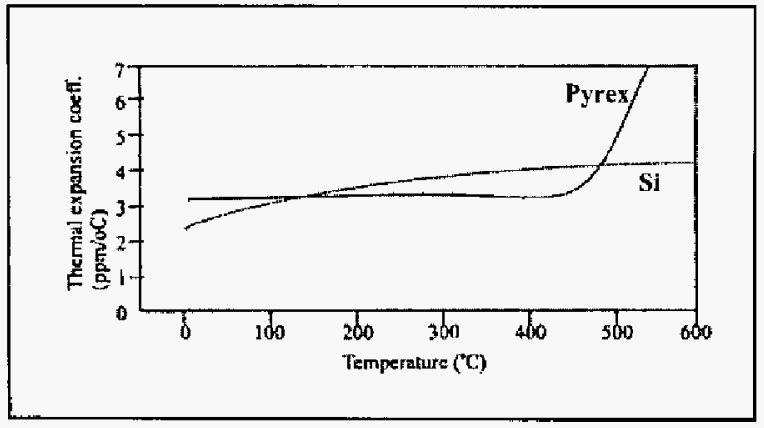

Figure 6: Thermal expansion coefficients of glass wafers compared with silicon [11]

It is assumed that due to the thermal mismatch at high temperature, thermal compressive stresses induced during cooling, cause the fracture at silicon-glass interface and specimen breaks at low pressure of 65 bars.

\section{CONCLUSION}

Glass tubes to silicon fusion bonding is a simple process for the fabrication of quality fluidic interconnects. The procedure is rather simple and needs only the standard semiconductor process equipment. The bond strength obtained is high enough for MEMS applications such as micro flow controller, micro reactor and for fluidics in general. Reducing the surface roughness of diced glass tubes can increase the bond strength. Additionally, smooth dicing and use of smaller glass tubes can reduce leaning of glass tubes.

Both silicon and silicon oxide layer can be chosen for good quality bonding depending upon the application. However silicon nitride can be excluded.

\section{REFERENCE}

[1] N. H. Bings, C. Wang, C. D. Skinner, C. L. Coyler, P. Thibbault, D. J. Harrison, "Microfluidic devices connected to fused silica capillaries with minimal dead volume" Anal. Chemistry 71 (1999), p. 32923296 .

[2] N. J. Moourlas, D. Jaeggi, A. I. Flannery, "Novel interconnections and channel technologies for microfluidics" S \& A 77, no. 1 (1999), p. 57-65.

[3] T. S. Harrison, "Packaging of the MIT microengine" S. M., Mass Inst. Technology, Cambridge MA 2000.

[4] T. S. Harrison, A. P. London and S. M. Spearing, "High temperature, high pressure fluid connections for power Microsystems" in Mater. Res. Soc. Proc., vol. 654, 2001, paper EE6.5.
[5] S. E. Shoaf, A. D. Feinerman, "Aligned Au-Si eutectic bonding of silicon structures", J. Vac. Sci. Tech. A 12(1) (1994), p. 19-22.

[6] T. J. You, S. Lee, W. Fang, Y. C. Tai, "Micromachined rubber O-ring microfluidic couplers" Proceedings MEMS Miyazaki, Japan (2000), p. 624-627.

[7] A. Puntambekar, C. H. Ahn, " Self aligning microfluidic interconnects with low dead volume" Proceedings of $\boldsymbol{\mu}$ Tas, Enschede, The Netherlands (2000), p. 323-326

[8] Marko Blom "On chip separation and sensing systems for hydrodynamic chromatography" University of Twente, Enschede, The Netherlands, 2000 .

[9] Yoav Peles, V. T. Sarkar, Todd S. Harrison, Christorpher Protz, Anna Mracek and S. Mark Spearing "Fluid packaging of mictoengine and microrocket Devices for high pressure and high tempratuer operation" J. Micromechanical Systems, Vol. 13, No. 1, February 2004.

[10] Christine Harendt, . Wolfgang Appel, Heinz-Gerd Graf, Bernd Hoefflinger and Elisabeth Penteker "Wafer fusion bonding and its application to silicon on insulator fabrication" J. Micromech. Microengg. 1 (1991) 145-151.

[11] M. C. Elwenspoek, H. Jansen "Silicon Micromachining" Cambridge University Press, 1998. 